\title{
Flavonoids in Benign Prostate Hypertrophy: Identification in Herbal Preparations and Molecular Docking Approach
}

\author{
Huda Mando 1,*(i), Ahmad Hassan ${ }^{1}$, Nathalie Moussa ${ }^{2}$ \\ 1 Department of Pharmaceutical Chemistry and Quality Control of Medicaments, Faculty of Pharmacy, Damascus \\ University, Damascus, Syria; hodamandomando@hotmail.com (H.M.), aha226@gmail.com (A.H.); \\ 2 Department of Pharmaceutical Chemistry and Quality Control of Medicaments, Faculty of Pharmacy, Al andalus \\ University for medical science, Tartus, Syria; n.mousa@au.edu.sy (N.M.); \\ * Correspondence: hodamandomando@hotmail.com (H.M.);
}

Scopus Author ID 55255180500

Received: 20.10.2021; Revised: 24.11.2021; Accepted: 27.11.2021; Published: 10.12.2021

\begin{abstract}
The benefits of phytotherapy in Benign prostatic hyperplasia (BPH) are of interest where they may lack side effects at long-term therapy. Through plant-derived preparations are Saw palmetto and Pumpkin seed oil. Evidence suggests that fatty acids, phytosterols, tocopherols, and flavonoids are the active components responsible for alleviating BPH symptoms. Flavonoids are reported to inhibit $\mathrm{BPH}$ through different mechanisms. Reducing inflammation and lowering reactive oxygen species are amongst the proposed mechanisms. In vitro studies highlighted the role of flavonoids in 5-alpha reductase II (5ARII) inhibitory activity. In this study, herbal preparations known to treat BPH were subjected to LC/MS/MS analysis integrated with multiple reaction monitoring (MRM) to identify the content of flavonoids. A molecular docking study was conducted on the assigned flavonoids to predict the binding mode and interaction with the targeted 3D- crystal structure of the human 5ARII enzyme. Results showed the existence of seven flavonoids and a polyphenol compound. Sakuranetin, Isorhamnetin, and Chlorogenic acid were not reported before. Molecular docking outcomes revealed that Astragalin, Isoquercitrin, Quercetin, and Chlorogenic acid have similar binding affinity to the reference Finasteride compound. These findings suggest flavonoids as potent potential inhibitors of 5ARII and could proceed to in vitro investigations.
\end{abstract}

Keywords: BPH; herbal preparations; Saw palmetto; flavonoids; LC-MS-MS; molecular docking.

(C) 2021 by the authors. This article is an open-access article distributed under the terms and conditions of the Creative Commons Attribution (CC BY) license (https://creativecommons.org/licenses/by/4.0/).

\section{Introduction}

Benign prostatic hyperplasia (BPH) is one of the most common geriatric male disorders worldwide, increasing prevalence [1]. The rate of incidence increases notably in aging males, with a progressive augment in prevalence to nearly $80 \%$ in men over 80 years of age [2]. Enlargement of prostate and boost in cell number is due to the stromal and epithelial proliferation and/or to impaired programmed cell death or apoptosis resulting in cellular accumulation. Androgens, growth factors, and neurotransmitters may participate either solely or in combination in the etiology of the hypertrophic process [3]. Treatment options of BPH are largely based on two classes of medications; alpha one-adrenergic antagonists ( $\alpha 1 \mathrm{AA})$ and 5-alpha reductase II inhibitors (5ARIIs) [4]. Being potent anti-inflammatory drugs, phosphodiesterase inhibitors provide additional options to treat prostatic inflammation [5]. FDA approved in October 2011 the usage of tadalafil for treatment of BPH. Combining an alpha-blocker and 5ARIIs may slightly ameliorate urinary symptoms [6]. Combination therapy 
between alpha one-adrenergic antagonists and 5ARII inhibitors is the gold benchmark for BPH remedy even though accompanied by significantly higher rates of erectile dysfunction(ED) and libido alterations (LA) [7]. Recently, the medical management of BPH has been largely based on phytotherapy. Blood pressure and sexual function are the main drawbacks of conventional therapies, mainly $\alpha 1 \mathrm{AA}$ and 5ARII inhibitors. Plant-derived preparations fill the need for treatment with fewer reverse effects [8]. Versatile plants are available for the handling of BPH with different mechanisms. Inhibition of 5ARII is one of the proposed mechanisms through which certain active components play a role in the mechanism of inhibition. Herbal remedies in the literature proved to benefit BPH by inhibition of 5AR include Alpinia officinarum, Brassica napus, Camellia sinensis, cucurbita seed oil, Lygodium japonicum, Pinus sp, Polygonum multiflorum Thunb, Rosa multiflora, and Serenoa repens. Animal studies revealed that Steroidal compounds, Lauric and myristic acids, stearic, oleic, palmitic and linoleic acids, daidzin, polyphenolic compounds, and Isoflavones alleviate symptoms by different mechanisms involving 5ARII inhibitory activity, anti-androgen activity, anti-proliferative activity, and anti-inflammatory activity [9]. No evident side effects were observed in human studies of $P$. africanum alone or in combination with stinging nettle extracts and proved to be effective in comparison with placebo. In one trial that lasted for 12 months, S. repens proved to be equal to tamsulosin in the medical treatment of symptoms accompanied with BPH [10]. Tolerability was significant and effectiveness similar to finasteride during 24 weeks of treatment with Serenoa repens and Urtica dioica [11].

Saw palmetto is the third best-selling plant as a food supplement in America [12]. There are more than 30 types of plants used to treat BPH. More than half of the formulations contained the dry fruit extract of Serenoa repens, while the remainder contained Prunus africana, rye pollen extract, betasitosterol, stinging nettle (Urtica dioica), and Cucurbita pepo [13,14]. In silico studies brought phytosterols, fatty acids, and tocopherols as potential inhibitors to 5ARII [15-17]. Efficacy and safety of polyphenol treatment in the prevention and treatment of BPH in vivo and in vitro have been reported in recent years [18]. In vitro studies bring-to-light Naringenin, Luteolin, Kaempferol [19,20], and Isoflavones [21] as active herbal components in several plant preparations used to relieve BPH symptoms. The whole-cell assay proved daidzein, genistein, and kaempferol to be better inhibitors of the type II isozyme than the type 1 [22].

Astragalin, the glycoside form of kaempferol, is known for its diverse therapeutic properties such as antioxidant, anti-inflammatory, and antiviral [23,24].

Quercetin-3-O-neohesperidoside and Rutin are the main components of multiple herbal preparations with anti-inflammatory effects [25]. In vitro, in vivo, and in silico studies brought Quercetin as a potent inhibitor of SARS-CoV 2 by preventing the entry of the virus in the host cell, binding the S protein, and inhibiting ACE2 receptors [23].

Isorhamnetin is an active ingredient in many plants mainly contained in Hippophae rhamnoides and Ginkgo biloba, with numerous effects on cardiovascular and cerebrovascular protection, anti-tumor, anti-inflammatory, and anti-oxidation activity [26].

In this study, herbal preparation containing Saw palmetto (figure 1) from retail pharmacies was assessed by identifying flavonoids via LC/MS/MS method. Molecular docking simulation of flavonoids and polyphenols identified in the studied herbal preparations was carried out on the crystal structure of 5ARII. A better understanding of binding mode and interactions will add insight to their potential application in BPH control. While previous molecular modeling studies of diverse structures were made on homology models [27], a 3D 
X-ray crystal structure of 5ARII has been deposited in a protein data bank recently [28]. Screening the herbal preparations for the content of flavonoids and studying the interactions with the targeted protein by molecular docking approach will support and strengthen the theories and studies that correlate the activity of herbal formulations to certain components. To our knowledge, this is the first study of molecular docking of flavonoids performed on the human 3D X-ray crystal structure of 5ARII.

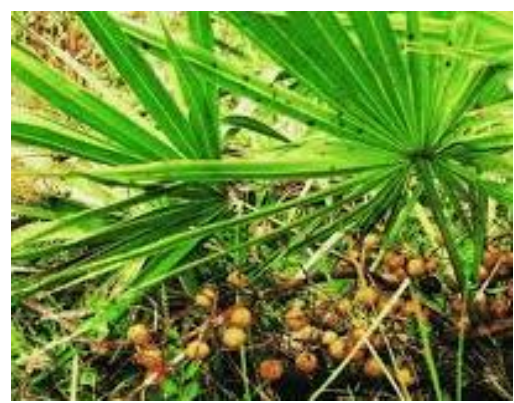

Figure 1. Saw palmetto.

\section{Materials and Methods}

\subsection{Identification of flavonoids.}

2.1.1. Reagents and samples.

Solvents were of LC/MS grade (Merck).Sawbal® tablets and Mivolis® capsules were supplied from a retail pharmacy.

\subsubsection{Sample preparation.}

Twenty tablets of Sawbal ${ }^{\circledR}$ were crushed, and twenty capsules of Mivolis ${ }^{\circledR}$ were opened and emptied. One gram of each content was dissolved in $10 \mathrm{~mL}$ methanol and sonicated for $2 \mathrm{~h}$. The methanol layer was taken and passed through a $0.22 \mu \mathrm{m}$ filter and injected directly to LC-MS-MS.

\subsubsection{LC-ESI-MS analysis.}

Agilent LC-MS-MS system (USA) liquid chromatography (Triple Quadrupole 6420 ) with electrospray ionization (ESI) equipped with mass spectrometry was used for the identification of flavonoids. The column was Eclipse XDB C18, $4.6 * 150 \mathrm{~mm}, 3.5 \mu \mathrm{m}$. The mobile gradient phase consisted of a mixture of (A) water acidified with $0.1 \%$ formic acid (B) acetonitrile. Gradient elution was applied as indicated: $15 \%-20 \%$ B for $0-5 \mathrm{~min}, 20 \%-28 \%$ B for 5-6 min, $28 \%$ B for 6-10 minutes, $28 \%-35 \%$ B for $10-12$ minutes, $35 \%$ B for $12-15$ minutes. The flow rate was $0.6 \mathrm{ml} / \mathrm{min}$, maintaining the temperature at $35^{\circ} \mathrm{C}$. The detection was carried out in the negative ion mode by a full scan range within 100 to $2000 \mathrm{~m} / \mathrm{z}$.

\subsubsection{Molecular docking of flavonoids.}

The molecular docking of flavonoids was performed using the Schrodinger suite of software (Maestro, version 121) with its scores and calculations. Molecular docking in the active site of the X-ray crystal structure of 5ARII went through the following steps [29]. 


\subsubsection{Ligand preparation.}

The 2D structures of the studied compounds were downloaded as standard structuredata file (SDF) format using the world's largest collection of freely accessible chemical information PubChem [30]. After that, they were converted into the protein data bank (PDB) format using the freely abundant open-source toolbox, Open Babel 3-1-1 [31]. The energy was minimized using potential liquid simulations (OPLS3) force field in Lig Prep in Maestro version 12.1 (Schrödinger, LCC, New York, 2019) [32,33]. The three-dimensional (3D) conformer generated for each ligand with the lowest energy was used during the docking procedure.

\subsubsection{Protein preparation.}

The 3D structure of 5ARII (PDB code: 7BW1, $2.8 \AA$ ) was retrieved from PDB and prepared. Water molecules and co-crystallized ligands were removed. Explicit hydrogen atoms were added. Bond orders and formal charges were adjusted, while disulfide bonds were created, and overlaps were checked. The corrected structure was subjected to energy minimization to relax any strain caused by the adjustment. The last step was preceded by repairing important protein errors such as incomplete residues [34].

\subsubsection{Grid generation.}

This step was obtained by Schrödinger in order to create a rigid network around the residues that form the functional binding groups at the binding site within the protein. The default box size is 20 angstroms and is centered on the default ligand.

Grids for molecular docking with Glide16 were calculated with a hydrogen bond constraint to glutamic acid 57 of 5ARII [35].

2.1.8. Extra precision (XP) molecular docking.

An extra precision (XP) glide docking was used to perform the docking and to predict the binding mode between the identified flavonoids and 5ARII. Compounds were flexibly docked with glide within the rigid binding site [36]. One docking hit with the least glide docking score indicating the most favorable pose is obtained for each ligand to be analyzed later [37]. Finally, the results were rendered in the work table as a pose viewer file.

\section{Results and Discussion}

\subsection{Identification of flavonoids.}

Acetonitrile was chosen as the organic phase due to its higher sensitivity and lower background than methanol. As for formic acid, it was added at a rate of $0.1 \%$ to the mobile phase, and it is facilitated better resolution by reducing peak tailing [38]. The negative ionization mode $[\mathrm{M}-\mathrm{H}]-$ was chosen because it gives an extensive MS-MS fragmentation compared to $[\mathrm{M}+\mathrm{H}]+[39]$. Flavonoids were recognized by LC-MS-MS data and information available in the literature, with subsequent confirmation by multiple reaction monitoring (MRM). This recognition provided by MS/MS has enormous advantages in reducing interference and enhancing sensitivity compared to single-SIM modulation [40]. MRM scan 
mode is the best way to restrain the accuracy with specific ion fragmentation from the precursor ion to its specific fragmentation ion (by daughter ion) [39].

In the MS-MS spectrum, the loss of glycosyl moieties in the positive and negative ionization modes, as well as the molecular fragments, is observed due to the retro Diels-Alder (RDA) [41] fragmentation pathway, which implies dissociation of the glycosides to their original components.

The chromatogram obtained by LC-MS-MS of Sawbal methanolic extract showed eight peaks in the full scan mode represented by Figure 1.

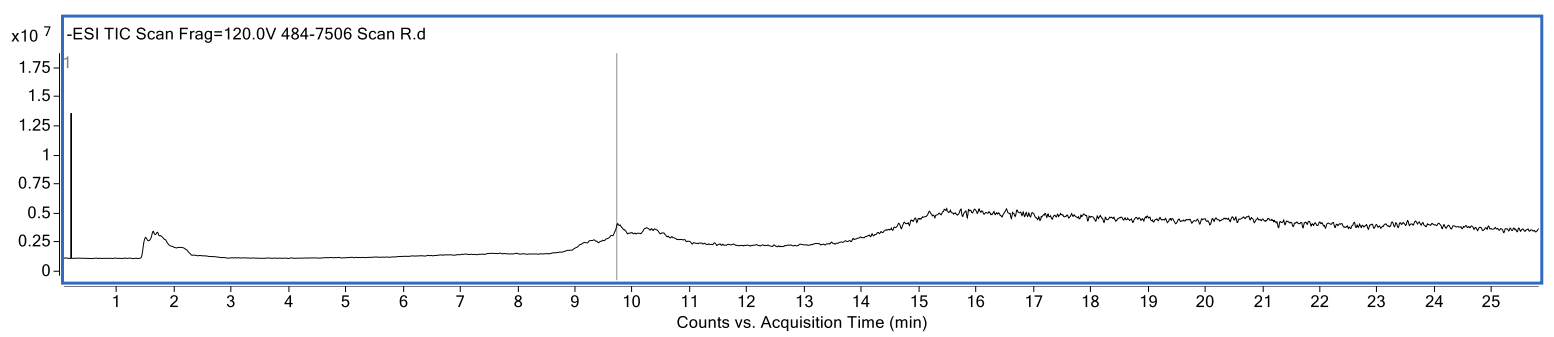

Figure 2. Chromatogram of Sawbal methanolic extract in the full scan mode.

Eight flavonoids were initially identified in the methanolic extract by mass, fragmentation mass spectrometry (molecular masses of potential components), and information available in the literature (Table 1). Most of the compounds identified gave the deprotonated molecule $[\mathrm{M}-\mathrm{H}]-$ representing the predominant precursor ions except for Quercetin 3-Oneohesperidoside, which gave the parent fragment without deprotonation, and Rosmarinic acid, which gave the fragment 357.2 which is $[\mathrm{M}-\mathrm{H}-2 \mathrm{H}]-$

Peak 1 (1.617) with a $[\mathrm{M}-\mathrm{H}]$ - ion $\mathrm{m} / \mathrm{z} 447$ and daughter ion at $\mathrm{m} / \mathrm{z} 285$ was identified as Astragaline. The daughter ion $\mathrm{m} / \mathrm{z} 285$ represents the fragment belonging to the kaempferol glycoside after cleavage of the glycoside molecule, as in Fig 2, [42].

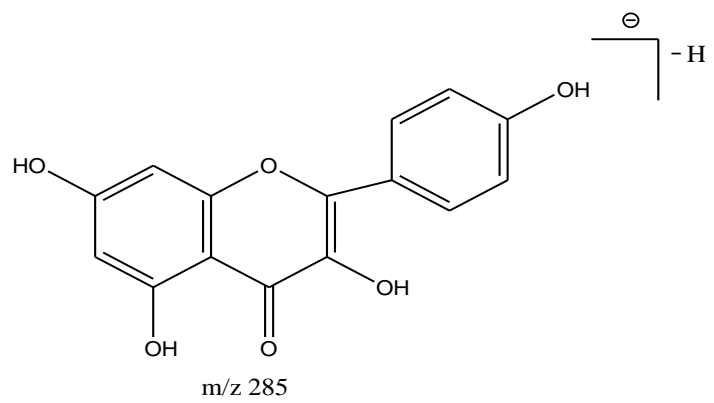

(a)

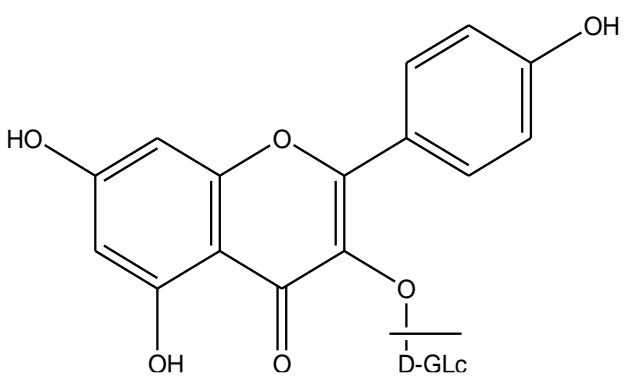

(b)

Figure 3. (a) Astragaline structure (b) ion $\mathrm{m} / \mathrm{z} 285$.

Peak 2 (1.628) with the fragment $610 \mathrm{Da}$ and daughter ion at $\mathrm{m} / \mathrm{z} 179$ was identified as Quercetin 3-O-neohesperidoside, as can be seen in Figure 3, [43].

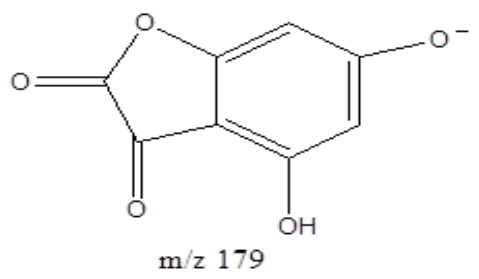

Figure 4. Fragment m/z 179 of Quercetin. 
Peak 3 (1.650) with a $[\mathrm{M}-\mathrm{H}]-$ ion $\mathrm{m} / \mathrm{z} 316.9$ and daughter ion at $\mathrm{m} / \mathrm{z} 179$ was identified as Myricetin [44] in Figure 4.

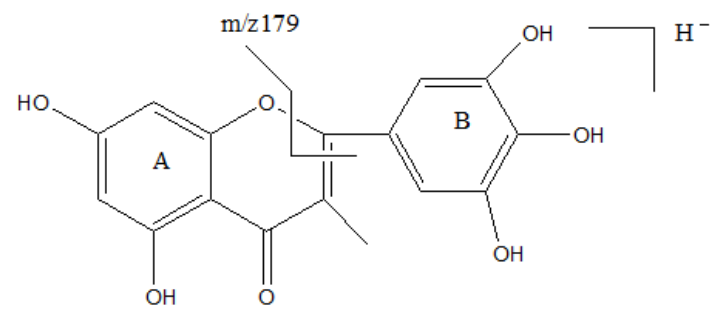

Figure 5. Fragment $\mathrm{m} / \mathrm{z} 179$ of Myricetin.

Isorhamentin at 2.116 was identified by the molecular ion $\mathrm{m} / \mathrm{z} 316.9$ and daughter ion 272.8, as shown in Figure 5 [45,46].

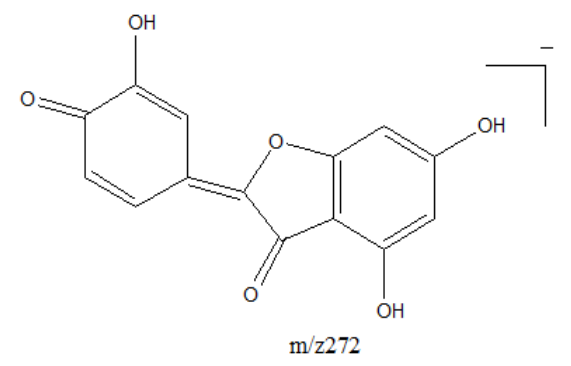

Figure 6. Fragment m/z 272 of Isorhamentin.<smiles>COc1cc(O)c2c(=O)c(O)c(-c3ccc(O)c(O)c3)oc2c1</smiles>

Figure 7. Fragment m/z 300 of Rutin.

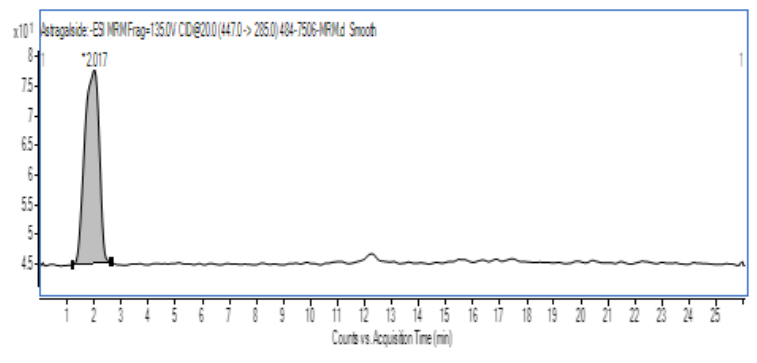

(a)

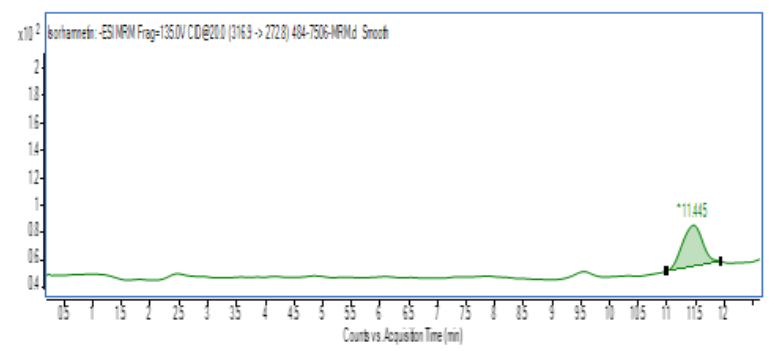

(c)

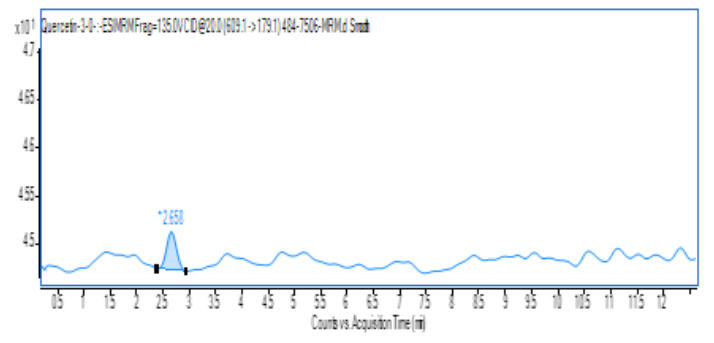

(b)

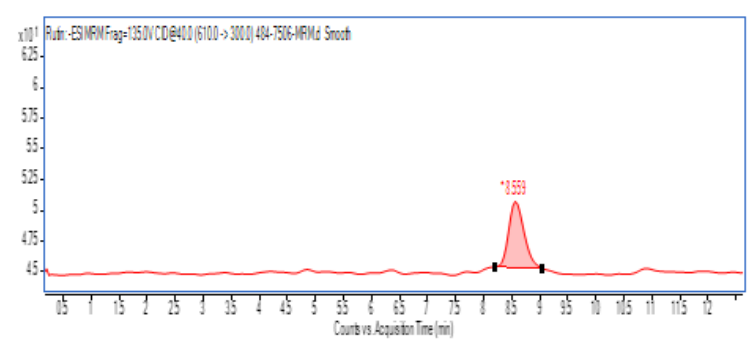

(d)

Figure 8. Chromatogram of flavonoids identified by MRM in methanolic extract of Sawbal@: (a) Astragaline; (b) Quercetin-3-O-neohesperidoside; (c) Isorhamnetin; (d) Rutin. 
Table 1. The flavonoids identified in methanolic extract of Sawbal® by LC-MS-MS.

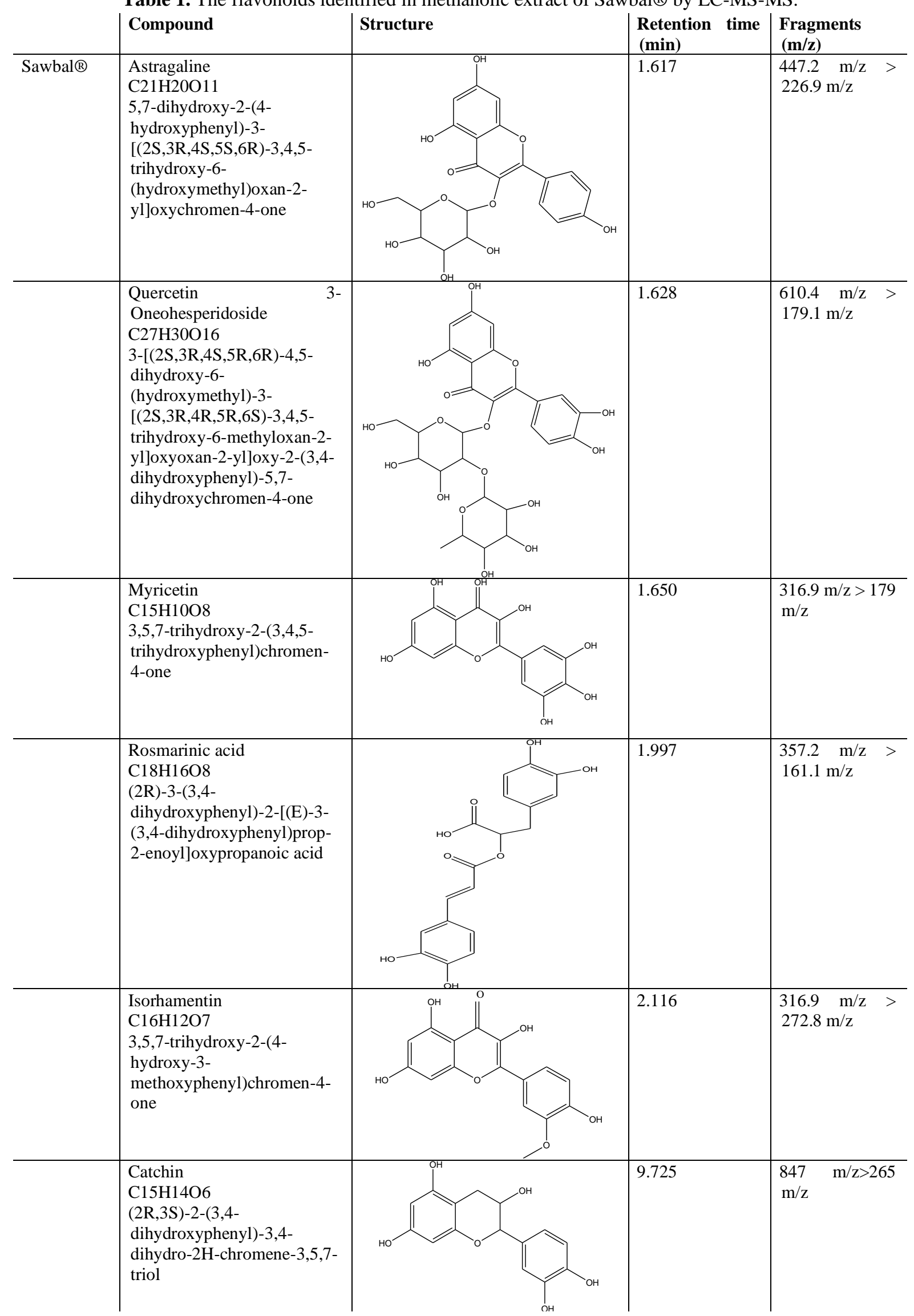




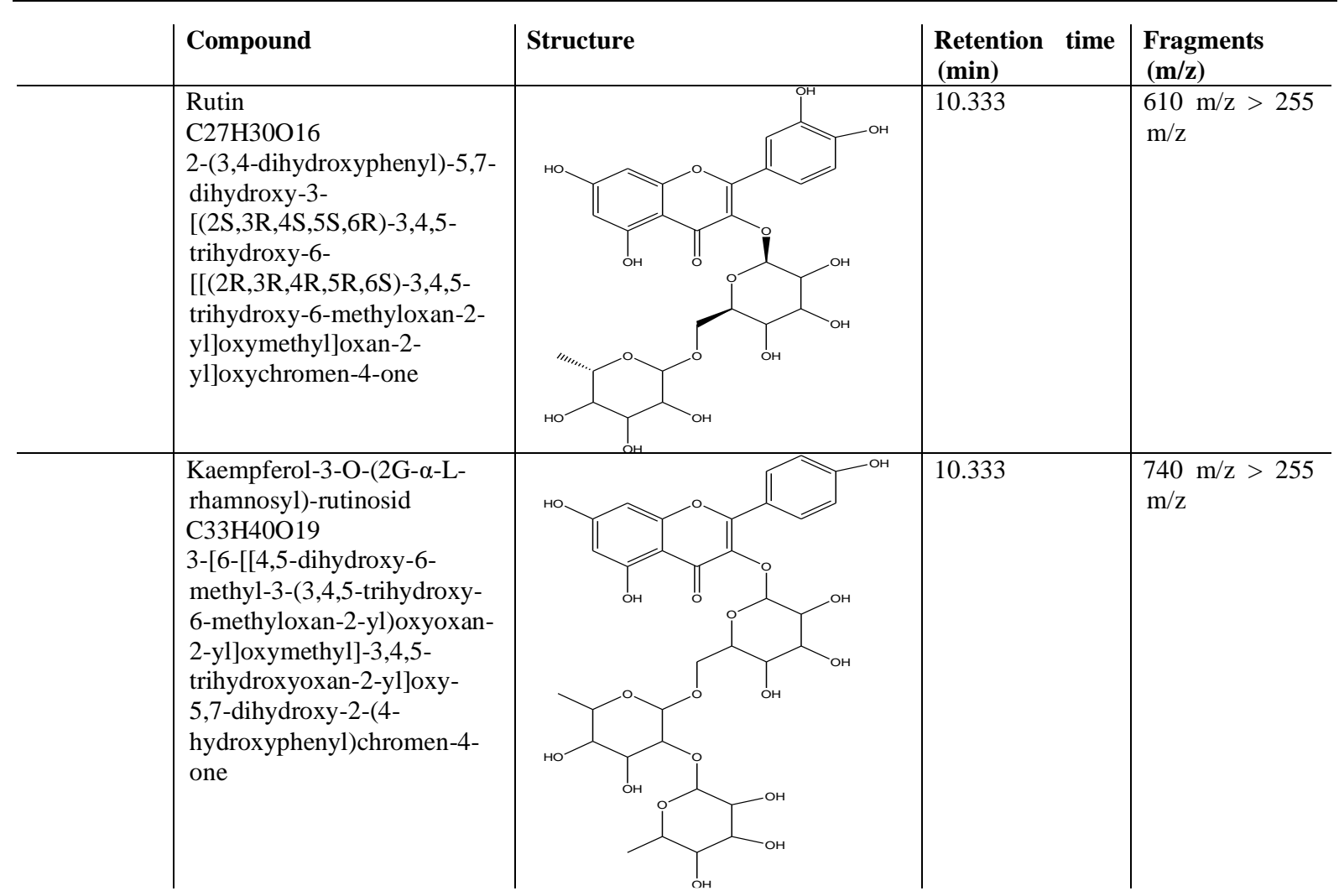

Peaks 4, 6, 7, and 8 were identified as Rosmarinic acid (1.997) [47], catchin (9.725) [45], Rutin (10.33) [46] (Figure 6), Kaempferol-3-O-(2G- $\alpha$-L-rhamnosyl)-rutinosid (10.33) respectively by their molecular and daughter ions (Table 1$)$.

After initiative identification of flavonoids in Sawbal®, MRM was applied to confirm the presence of the initially assigned ones. During MRM analysis, certain daughter ions are selected through the second quadrupole, transitioning from the molecular ion-specific to its production. $447>285 \mathrm{~m} / \mathrm{z}, 316.9>272.8 \mathrm{~m} / \mathrm{z}, 610.4 \mathrm{~m} / \mathrm{z}>179.1 \mathrm{~m} / \mathrm{z}, 610>300 \mathrm{~m} / \mathrm{z}$ were chosen as the qualifier ion transition of Astragaline, Isorhamnetin, Quercetin-3-Oneohesperidoside, and Rutin respectively. Figure 7, Shows the chromatograms of the identified flavonoids in methanolic extract of Sawbal® by LC-MS-MS/ MRM mode.

The chromatogram obtained by LC-MS-MS of Mivolis ${ }^{\circledR}$ methanolic extract in the full scan mode is represented in Figure 8.

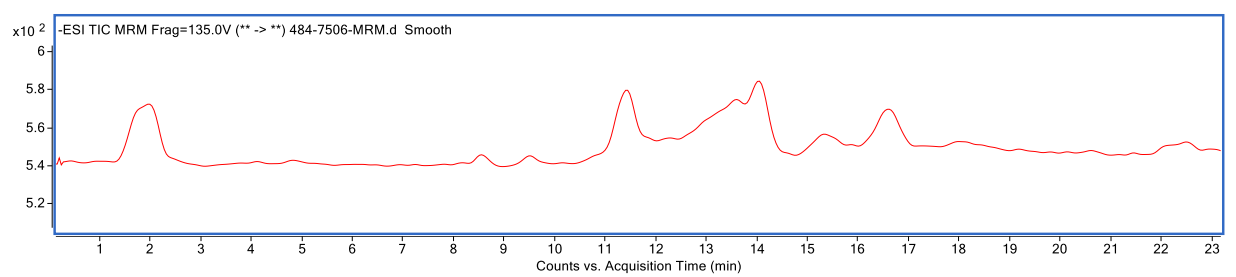

Figure 9. Chromatogram of Mivolis ${ }^{\circledR}$ methanolic extract in the full scan mode.

Chlorogenic acid and 7 flavonoids are identified in Mivolis ${ }^{\circledR}$ methanolic extract by LCMS-MS- MRM. The presence of chlorogenic acid is confirmed by the precursor ion $\mathrm{m} / \mathrm{z} 353$ and daughter ion m/z 191 expressing quinic acid (Fig 10), [48].

The presence of a Sakuranetindimer polymer is also confirmed by the molecular fragment $\mathrm{m} / \mathrm{z} 551$, which results from the meeting of two Sakuranetin molecules and the exit of a water molecule and $\mathrm{H} 2$ and the daughter fragment m/z 197. Previous studies have shown 
the existence of carbon-carbon bonds between a flavonoid and another, such as Sakuranetin 3,8 homodimer and Chamaejasmin [49].

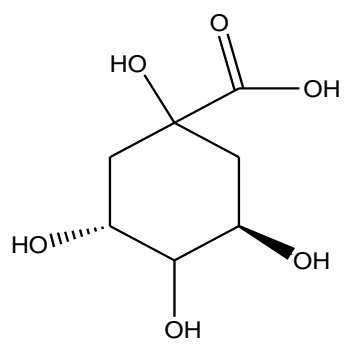

Figure 10. Fragment m/z 191 of quinic acid.
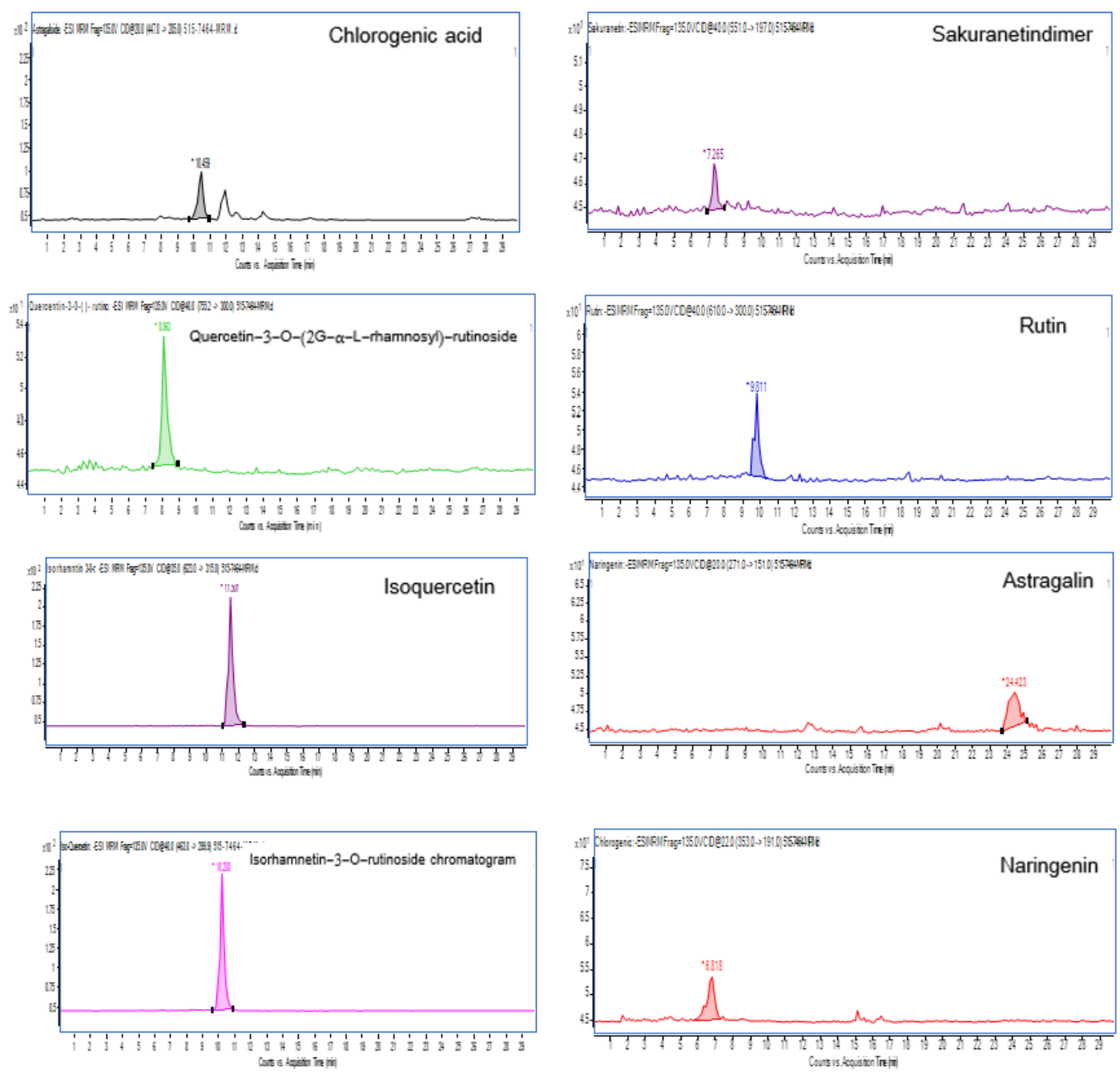

Figure 11. Chromatogram of Chlorogenic acid and flavonoids identified by MRM in methanolic extract of Mivolis®.

Quercetin-3-O-(2G- $\alpha$-L-rhamnosyl)-rutinoside is defined based on precursor fragment $\mathrm{m} / \mathrm{z} 755.2$ and daughter fragment $\mathrm{m} / \mathrm{z} 300$ [46]. Similarly, the compound Rutin is defined based on the molecular ion $\mathrm{m} / \mathrm{z} 610$ and the daughter fragment $\mathrm{m} / \mathrm{z} 300$, and according to a recent study, this compound inhibits the protease enzyme of SARS-CoV-2 [50].

Figure 11 depicts the chromatogram of Chlorogenic acid and flavonoids identified by MRM in methanolic extract of Mivolis®.

Isoquercetin, Astragalin, Isorhamnetin-3-O-rutinoside, and Naringenin are identified by the ions $\mathrm{m} / \mathrm{z} 463.0 / 299.9$ [51], 447.0/285 [43] and 623/315 [52], 272/151 [53,54] 
respectively. The fragmentation pattern of Isorhamnetin-3-O-rutinoside is shown in Figure 12. The product ion m/z 151 in Naringenin is illustrated in Figure 13.

Astragalin inhibits SARS-CoV-2, according to a recent study [24], in addition to its anti-inflammatory activity. The flavonone Naringenin is present in many vegetables and fruits and has strong antioxidant, antiviral and anti-inflammatory, properties [55-57]. Its beneficial effect against SARS-CoV-2 is exerted by inhibiting the main protease and reducing ACE2 activity [24]. The identified active components of Mivolis ${ }^{\circledR}$ are listed in Table 2.<smiles>CCc1ccc(C2CC(=O)c3c(O)cc(O)cc3O2)cc1</smiles>

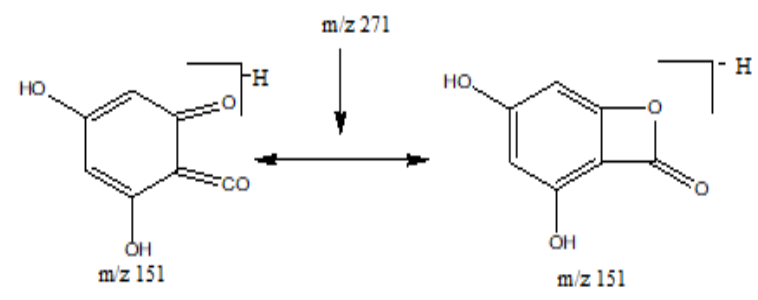

Figure 13. Interpretation of the fragment m/z 151 in Naringenin.

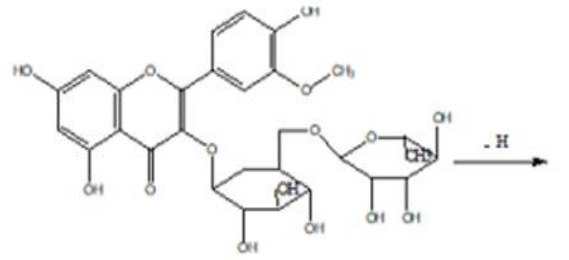

$\sin 204$

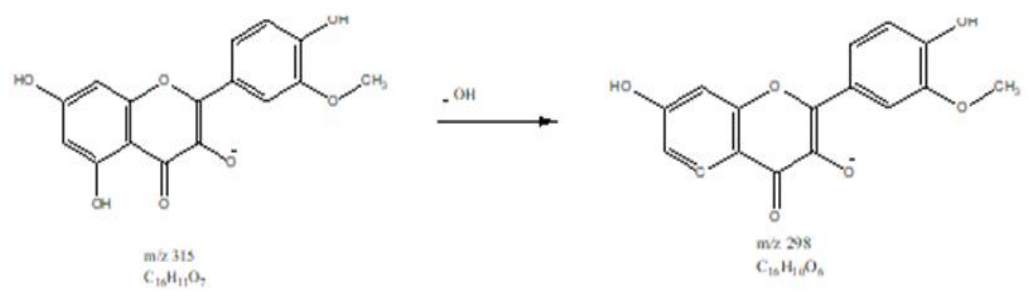

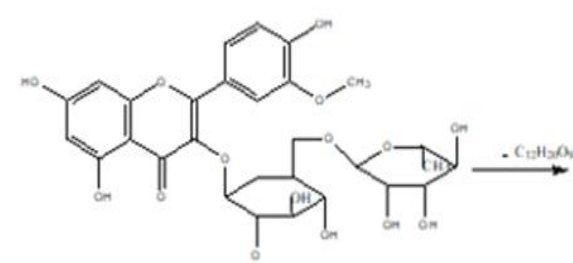

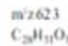

Figure 12. Interpretation of the fragments of Isorhamnetin-3-O-rutinoside.

Table 2. The flavonoids identified in methanolic extract of Mivolis® by LC-MS-MS/MRM mode.

\begin{tabular}{|c|c|c|c|c|}
\hline Compound & Structure & MW & $\begin{array}{l}\text { Molecular } \\
\text { formula }\end{array}$ & $\begin{array}{c}\text { Fragments } \\
\mathbf{m} / \mathbf{z}\end{array}$ \\
\hline $\begin{array}{l}\text { Chlorogenic acid } \\
\text { C16H18O9 } \\
\text { (1S,3R,4R,5R)-3-[(E)-3-(3,4- } \\
\text { dihydroxyphenyl)prop-2-enoyl]oxy- } \\
\text { 1,4,5-trihydroxycyclohexane-1- } \\
\text { carboxylic acid }\end{array}$ & & 354.31 & C16H18O9 & $353>191$ \\
\hline $\begin{array}{l}\text { Sakuranetin } \\
\text { C16H14O5 } \\
\text { (2S)-5-hydroxy-2-(4- } \\
\text { hydroxyphenyl)-7-methoxy-2,3- } \\
\text { dihydrochromen-4-one }\end{array}$ & & 286.26 & C16H14O5 & $551>197$ \\
\hline
\end{tabular}


Quercetin-3-O-(2G- $\alpha$-Lrhamnosyl)-rutinoside $\mathrm{C} 33 \mathrm{H} 40 \mathrm{O} 20$

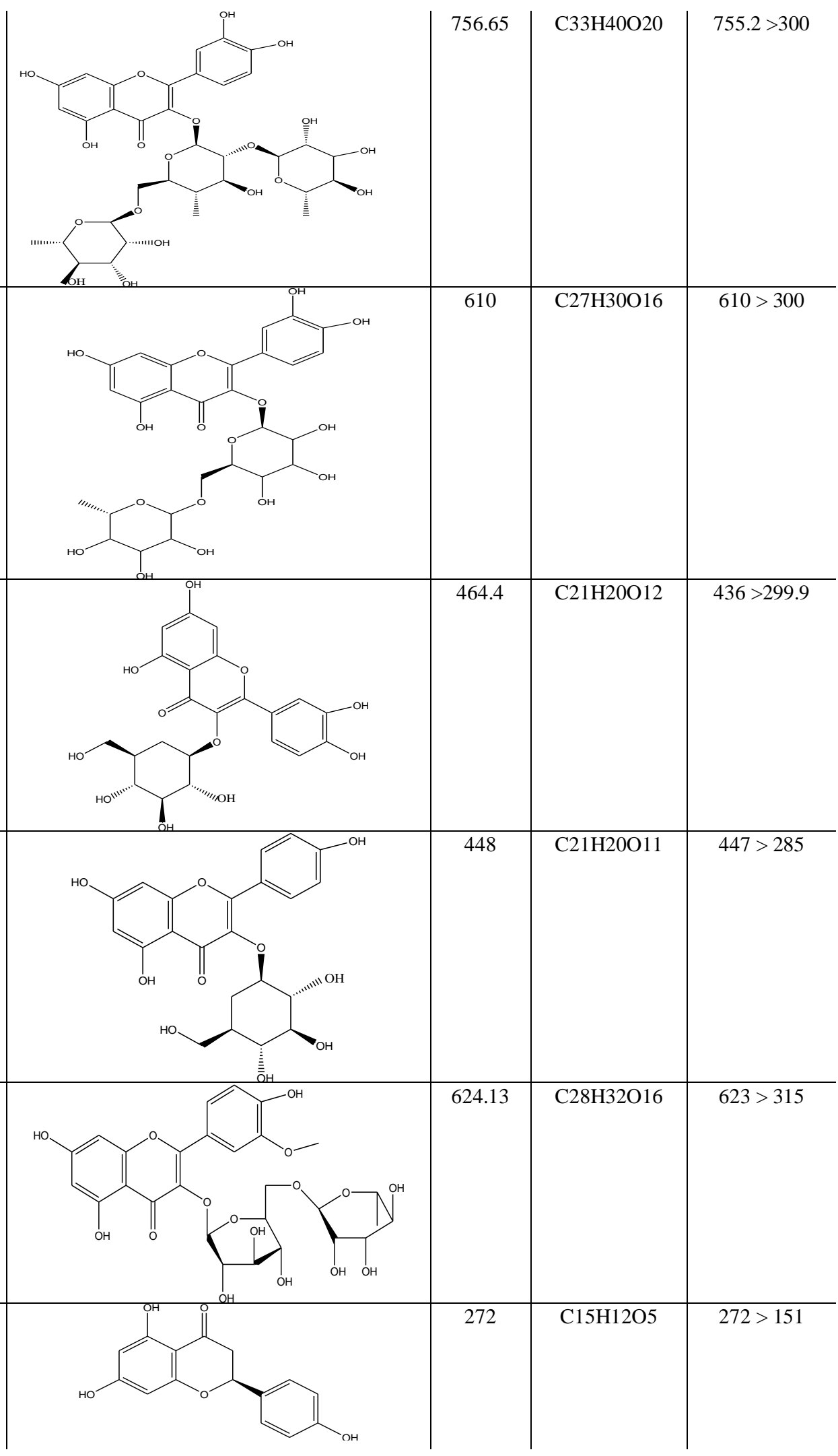

Table 3. Types of interactions between the flavonoids and the binding site of 5ARII. C28H32O16

5,7-dihydroxy-2-(4-hydroxy-3methoxyphenyl)-3-

[(2S,3R,4S,5S,6R)-3,4,5-

trihydroxy-6-[[(2R,3R,4R,5R,6S)-

3,4,5-trihydroxy-6-methyloxan-2-

yl]oxymethyl]oxan-2-

yl]oxychromen-4-one

Naringenin

C15H12O5

5,7-dihydroxy-2-(4-

hydroxyphenyl)-2,3-

dihydrochromen-4-one

Charged - Charged + hydrophobic

\begin{tabular}{l|l|l|l|l|l|l|l} 
& Charged - & Charged + & hydrophobic & Polar & H-bond & pi-pi & Glide /score \\
\hline Finasteride & Glu57 & & TYR91,33,107. & Gln56,Ser31 & Glu57 & & -8.79 \\
\hline & & & PHE223,219,118.ALA & & Arg114 & & \\
\hline & & & 24, & & TYR91 & & \\
\hline & & & LEU224,111,23,20.C & & & & \\
\hline Chlorogenic & ASP164, & ARG171, & TYR178,98,33.LEU16 & ASN193,160 & ARG171, & TRP53 & -8.779 \\
\hline acid & GLU197 & $105,227,9$ & 7,224,TRP53PHE194, & .HIE231 & 227.TYR1 & &
\end{tabular}




\begin{tabular}{|c|c|c|c|c|c|c|c|}
\hline & Charged - & Charged + & hydrophobic & Polar & H-bond & pi-pi & Glide /score \\
\hline & & 4.LYS35. & & & 78.ASP16 & & \\
\hline & & & & & 4,ASN160 & & \\
\hline & & & & & ,197,HIE2 & & \\
\hline & & & & & 31 & & \\
\hline \multirow[t]{3}{*}{ Astragaline } & GLU57,19 & ARG94,2 & TYR91,107,33.PHE19 & SER31,220. & SER220. & PHE216, & -8.225 \\
\hline & 7 & 27,114 & $4,216,219,223,218 . \mathrm{LE}$ & ASN160.GL & GLU57.A & 219 & \\
\hline & & & U111,224.TRP53,201 & N56 & RG94 & & \\
\hline \multirow[t]{3}{*}{ Isoquercetin } & GLU57,19 & ARG94,2 & LEU167,PHE186, & SER31,220. & ASN193 & & -7.679 \\
\hline & 7,ASP164 & $27,114 . \mathrm{H}$ & ALA192.PHE234 & ASN160,GL & GLY191 & & \\
\hline & & P90 & & N56 & SER190 & & \\
\hline Quercetin- & GLU197,5 & ARG114, & PHE194,223,118,119, & SER31,220. & TYR91,98 & PHE33,2 & -7.619 \\
\hline $3-\mathrm{O}-$ & 7,ASP164 & $227,94 . \mathrm{H}$ & 216.LEU224,167,111. & ASN193,160 & ,33.GLU5 & 23,118 & \\
\hline neohesperid & & P90. & TYR91,98,107.TRP53 & .GLN56.AG & 7.ARG94 & & \\
\hline oside & & & CYS119. & N122.HE23 & & & \\
\hline \multirow[t]{4}{*}{ Rutin } & GLu57,19 & ARG227, & LEU20,224,111,167.T & SER31,220. & GLU57.A & PHE194. & -6.777 \\
\hline & 7.ASP164 & 94,90 & YR98,107,91,33.PHE & ASN193,160 & SP164.TY & ARG94 & \\
\hline & & & $118,223,216,219,194$ & GLN56 & R91,33.S & & \\
\hline & & & TRP53,201.CYS119 & & ER31 & & \\
\hline \multirow[t]{4}{*}{ Isorhamnitin } & GLu57,19 & ARG94,1 & PHE216,194,223,219, & SER31.ASN & TYR91.A & ARG94. & -6.762 \\
\hline & 7 & 14.HIP90 & 118.LEU224,111,TYR & 160.GLN56. & RG94.GL & TRP53 & \\
\hline & & & 91,33,107.TRP201,53 & & U197 & & \\
\hline & & & .CYS119 & & & & \\
\hline \multirow[t]{4}{*}{ Sakuranetin } & GLU197,5 & ARG94.HI & PHE194,223,118,219, & ASN160,193 & GLU197.T & ARG94 & -6.729 \\
\hline & 7 & P90 & 216.TYR107,33,91.T & GLN56 & YR91.LE & & \\
\hline & & & RP53,201.CYS119.LE & & U111 & & \\
\hline & & & $\mathrm{U} 224,111$ & & & & \\
\hline Isorhamnetin & GLu197,5 & ARG94,1 & PHE216,223,194,219, & ASN160.GL & GLU197. & TRP53.A & -6.300 \\
\hline$-3-\mathrm{O}-$ & 7 & 14.HIP90 & 118.TRP201,53.TYR9 & N56.SER31 & ARG94.T & RG94 & \\
\hline \multirow[t]{2}{*}{ rutinoside } & & & 1,33,107.LEU111,224 & & YR91. & & \\
\hline & & & CYS119 & & & & \\
\hline \multirow[t]{3}{*}{ Naringenin } & GLU57,19 & HIP90.AR & TYR98,91,33.PHE216 & ASN160,193 & TYR91.A & PHE118 & -6.109 \\
\hline & 7.ASP164 & G94 & ,223,118,194.LEU224 & & SP164.AS & & \\
\hline & & & TRP53.CYS119 & & N160 & & \\
\hline
\end{tabular}

\subsection{Molecular docking of flavonoids.}

Root mean square deviation (RMSD) between the crystal ligand and re-docked ligand (finasteride) was less than the X-RAY resolution (1.5), revealing acceptable harmony between the experimental and predicted binding pose [58].

The extra precision glide docking scores for the identified flavonoids ranged between 6.109 and -8.779. The score of finasteride as a potent reference 5ARII was -8.79. Chlorogenic acid and Astragalin fit well in the 5ARII binding site with a glide score close to finasteride (Figures 13, 14, and 15). Astragalin, Quercetin-3-O-neohesperidoside, and Rutin can create a hydrogen bond with GLU57 as finasteride do, where Quercetin-3-O-neohesperidoside, Rutin, Isorhamnitin, Sakuranetin, Isorhamnetin-3-O-rutinoside, and Naringenin can bind to TYR91 with a hydrogen bond as in finasteride (Table 3). None of the compounds bonded with ARG114 as finasteride. All the compounds participated in pi -pi attacking (except Isoquercetin) by their TRP and PHE residues. ARG94 was involved in pi-pi stacking in Rutin, Isorhamentin, Sakuranetin, and Isorhamnetin-3-O-rutinoside. Although $\pi-\pi$ stacking is particularly known for aromatic rings where about $60 \%$ of aromatic rings show this interaction [59], ARG also can engage in such interaction via delocalized $\pi$-system of sp2-hybridized atoms of its guanidinium group [60]. Quercetin-3-O-neohesperidoside and Rutin bind with five hydrogen bonds where GLU57 and TYR91 are part of these bonds and finasteride. Chlorogenic acid has the lowest docking score among the identified polyphenols with hydrogen donating properties [61] and salt bridge interaction [62], suggesting stable ligand-enzyme complexes and well fit binding poses. 


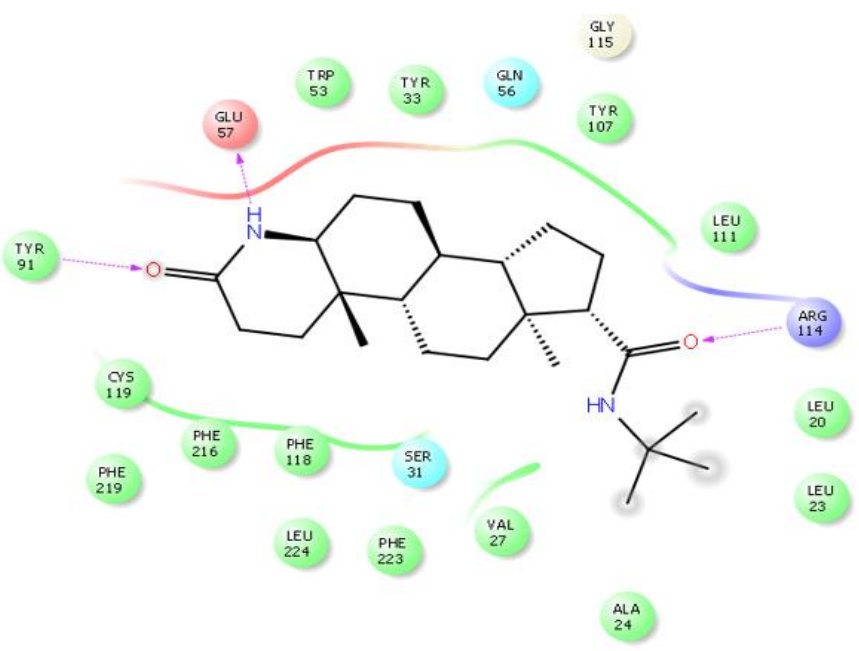

Figure 14. Schematic representation of the interactions between Dihydrofinasteride and 5ARII binding site. Hydrogen bonds with GLU57, TYR 91, and ARG114.

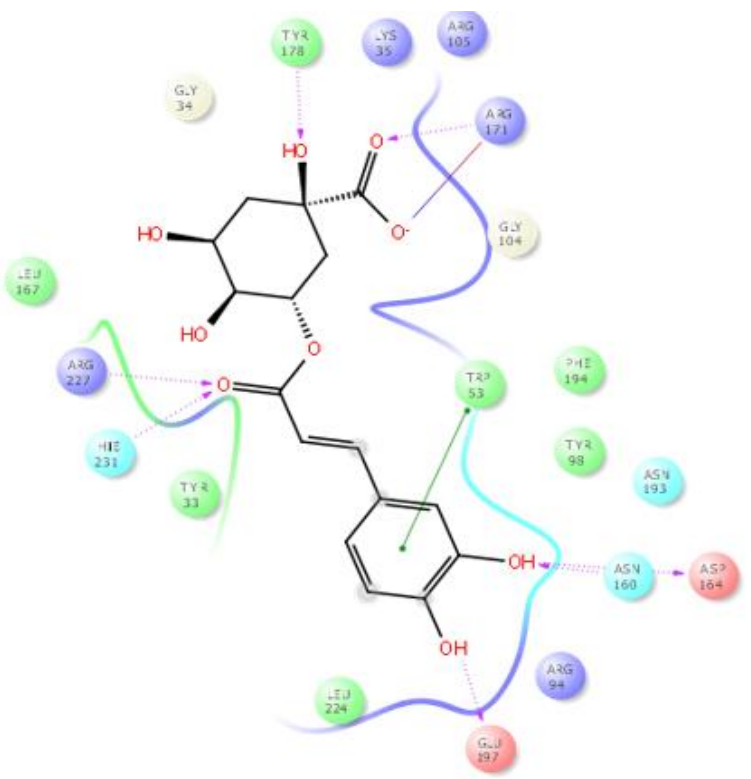

Figure 15. Schematic representation of the interactions between Chlorogenic acid and 5ARII binding site. Hydrogen bonds with TYR178, ARG171, ARG227, HIE231, GLU197, ASN160, and ASP164. Pi-pi stacking with TRP53. Salt bridge with ARG171.

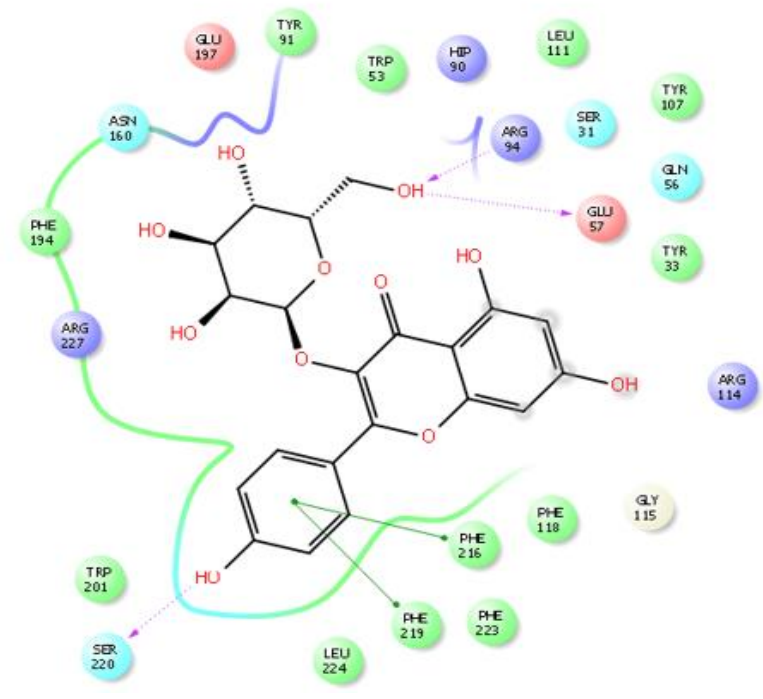

Figure 16. Schematic representation of the interactions between Astragaline and 5ARII binding site. Hydrogen bonds with ARG94, GLU57, and SER220. Pi-pi stacking with PHE216, PHE219. 


\section{Conclusions}

Different types of inhibitors of 5ARII inhibitors were developed during the last decade. In this study, we identified flavonoids in products containing Serenoa repens. MRM mode integrated with LC-MS-MS ascertained the presence of 7 flavonoids beside Chlorogenic acid. Isorhamnitin, Sakuranetin, and Chlorogenic acid were identified with no previous reports about their presence in such botanical preparations. Identification of these compounds may enhance consumer interest, augment sales, and boost the value of their preparations. Combining Molecular docking studies with other in vitro and in vivo provides a better understanding of binding modes and enhances the hypothesis of active components' activity. Chlorogenic acid, a potent antioxidant polyphenol, exhibited high affinity towered 5ARII with7 hydrogen bonds, $\pi$ - $\pi$ stacking, salt bridge, and hydrophobic interactions. While salt bridges are considered the strongest inorganic interactions, they can be used to design the strongest interactions in ligandprotein complexes and thus the strongest inhibition of the enzyme. Flavonoids displayed good interactions with 5ARII implying them as potent inhibitors close to finasteride. This is the first molecular docking study on flavonoids where they appeared as potential potent inhibitors, along with Chlorogenic acid as a promising lead 5ARII inhibitor.

\section{Funding}

This research received no external funding.

\section{Acknowledgments}

This research has no acknowledgment.

\section{Conflicts of Interest}

The authors declare no conflict of interest.

\section{References}

1. Cormio, L.; Calò, B.; Falagario, U.; Iezzi, M.; Lamolinara, A.; Vitaglione, P.; Silecchia, G.; Carrieri, G.; Fogliano, V.; Iacobelli, S.; Natali, P.G.; Piantelli, M. Improvement of urinary tract symptoms and quality of life in benign prostate hyperplasia patients associated with consumption of a newly developed whole tomatobased food supplement: a phase II prospective, randomized double-blinded, placebo-controlled study. Journal of Translational Medicine 2021, 19, https://doi.org/10.1186/s12967-020-02684-3.

2. Bortnick, E.; Brown, C.; Simma-Chiang, V.; Kaplan, S.A. Modern best practice in the management of benign prostatic hyperplasia in the elderly. Therapeutic Advances in Urology 2020, 12, https://doi.org/10.1177/1756287220929486.

3. Roehrborn, C. Pathology of benign prostatic hyperplasia. Int J Impot Res 2008, 20, 11-18, https://doi.org/10.1038/ijir.2008.55.

4. DeWitt, M.E.; Gill, B.C.; Ulchaker, J.C. Cost Comparison of Benign Prostatic Hyperplasia Treatment Options. Curr. Urol. Rep 2019, 20, https://doi.org/10.1007/s11934-019-0907-3.

5. Peixoto, C.A., Gomes, F.O. The role of phosphodiesterase-5 inhibitors in prostatic inflammation: a review. $J$ Inflamm 2015, 12, https://doi.org/10.1186/s12950-015-0099-7.

6. Pattanaik, S.; Mavuduru, R.S.; Panda, A.; Mathew, J.L.; Agarwal, M.M.; Hwang, E.C.; Lyon, J.A.; Singh, S.K.; Mandal, A.K. Phosphodiesterase inhibitors for lower urinary tract symptoms consistent with benign prostatic hyperplasia. Cochrane Database of Systematic Reviews 2018, 11, https://doi.org/10.1002/14651858.CD010060.pub2.

7. Favilla, V.; Russo, G.I.; Privitera, S.; Castelli, T.; Giardina, R.; Calogero, A.E.; Condorelli, R.A.; La Vignera, S.; Cimino, S.; Morgia, G. Impact of combination therapy 5-alpha reductase inhibitors (5-ARI) plus alphablockers $(\mathrm{AB})$ on erectile dysfunction and decrease of libido in patients with LUTS/BPH: a systematic review with meta-analysis. The Aging Male 2016, 19, 175-181, https://doi.org/10.1080/13685538.2016.1195361. 
8. Katz, A.E. Flavonoid and Botanical Approaches to Prostate Health. The Journal of Alternative and Complementary Medicine 2002, 8, 813-821, https://doi.org/10.1089/10755530260511829.

9. Azimi, H.; Khakshur, A.-A.; Aghdasi, I.; Fallah-Tafti, M.; Abdollahi, M. A Review of Animal and Human Studies for Management of Benign Prostatic Hyperplasia with Natural Products: Perspective of New Pharmacological Agents. Inflammation \& Allergy - Drug Targets (Discontinued) 2012, 11, 207-221, https://doi.org/10.2174/187152812800392715.

10. Debruyne, F.; Koch, G.; Boyle, P.; Da Silva, F.C.; Gillenwater, J.G.; Hamdy, F.C.; Perrin, P.; Teillac, P.; Vela-Navarrete, R.; Raynaud, J.P. Comparison of a phytotherapeutic agent (Permixon) with an alpha-blocker (Tamsulosin) in the treatment of benign prostatic hyperplasia: a 1-year randomized international study. European urology 2002, 41, 497-506; discussion 506-497.

11. Sökeland, J. Combined sabal and urtica extract compared with finasteride in men with benign prostatic hyperplasia: analysis of prostate volume and therapeutic outcome. BJU International 2000, 86, 439-442, https://doi.org/10.1046/j.1464-410x.2000.00776.x.

12. Jaiswal, Y.; Weber, D.; Yerke, A.; Xue, Y.; Lehman, D.; Williams, T.; Xiao, T.; Haddad, D.; Williams, L. A substitute variety for agronomically and medicinally important Serenoa repens (Saw palmetto). Scientific Reports 2019, 9, https://doi.org/10.1038/s41598-019-41150-z.

13. McClure, M.W. An overview of holistic medicine and complementary and alternative medicine for the prevention and treatment of BPH, prostatitis, and prostate cancer. World Journal of Urology 2002, 20, 273284, https://doi.org/10.1007/s00345-002-0292-1.

14. Pagano, E.; Laudato, M.; Griffo, M.; Capasso, R. Phytotherapy of Benign Prostatic Hyperplasia. A Minireview. Phytotherapy Research 2014, 28, 949-955, https://doi.org/10.1002/ptr.5084.

15. Governa, P.; Giachetti, D.; Biagi, M.; Manetti, F.; De Vico, L. Hypothesis on Serenoa repens (Bartram) small extract inhibition of prostatic $5 \alpha$-reductase through an in silico approach on $5 \beta$-reductase $\mathrm{x}$-ray structure. Peer J. 2016, 22, https://doi.org/10.7717/peerj.2698.

16. Mando, H.; Hassan, A.; Gharaghani, S. Novel and Predictive QSAR Model for Steroidal and Nonsteroidal $5 \alpha$ - Reductase Type II Inhibitors. Curr Drug Discov Technol. 2021, 18, 317-332, https://doi.org/10.2174/1570163817666200324170457.

17. Khantham, C.; Yooin, W.; Sringarm, K.; Sommano, S.R.; Jiranusornkul, S.; Carmona, F.D.; Nimlamool, W.; Jantrawut, P.; Rachtanapun, P.; Ruksiriwanich, W. Effects on Steroid 5-Alpha Reductase Gene Expression of Thai Rice Bran Extracts and Molecular Dynamics Study on SRD5A2. Biology 2021, 10, https://doi.org/10.3390/biology10040319.

18. Mitsunari, K.; Miyata, Y.; Matsuo, T.; Mukae, Y.; Otsubo, A.; Harada, J.; Kondo, T.; Matsuda, T.; Ohba, K.; Sakai, H. Pharmacological Effects and Potential Clinical Usefulness of Polyphenols in Benign Prostatic Hyperplasia. Molecules 2021, 26, https://doi.org/10.3390/molecules26020450.

19. Han, H.Y.; Shan, S.; Zhang, X.; Wang, N.L.; Lu, X.P.; Yao, X.S. Down-regulation of prostate specific antigen in LNCaP cells by flavonoids from the pollen of Brassica napus L. Phytomedicine 2007, 14, 338-343, https://doi.org/10.1016/j.phymed.2006.09.005.

20. Bektic, J.; Guggenberger, R.; Spengler, B.; Christoffel, V.; Pelzer, A.; Berger, A.P.; Ramoner, R.; Bartsch, G.; Klocker, H. The flavonoid apigenin inhibits the proliferation of prostatic stromal cells via the MAPKpathway and cell-cycle arrest in G1/S. Maturitas 2006, 55, S37-S46, https://doi.org/10.1016/j.maturitas.2006.06.015.

21. Chen, M.Y.; Yan, S.C.; Yin, C.P.; Ye, L.; Zhang, M.K.; Yang, J.; Liu, J.H. Red clover isoflavones inhibit the proliferation and promote the apoptosis of benign prostatic hyperplasia stromal cells. Zhonghua Nan Ke Xue, 2010, 16, 34-39.

22. Hiipakka, R.A.; Zhang, H.-Z.; Dai, W.; Dai, Q.; Liao, S. Structure-activity relationships for inhibition of human 5 $\alpha$-reductases by polyphenols. Biochemical Pharmacology 2002, 63, 1165-1176, https://doi.org/10.1016/s0006-2952(02)00848-1.

23. Ghidoli, M.; Colombo, F.; Sangiorgio, S.; Landoni, M.; Giupponi, L.; Nielsen, E.; Pilu, R. Food Containing Bioactive Flavonoids and Other Phenolic or Sulfur Phytochemicals With Antiviral Effect: Can We Design a Promising Diet Against COVID-19? Frontiers in Nutrition 2021, 8, https://doi.org/10.3389/fnut.2021.661331.

24. Hiremath, S.; Kumar, H.D.V.; Nandan, M.; Mantesh, M.; Shankarappa, K.S.; Venkataravanappa, V.; Basha, C.R.J.; Reddy, C.N.L. In silico docking analysis revealed the potential of phytochemicals present in Phyllanthus amarus and Andrographis paniculata, used in Ayurveda medicine in inhibiting SARS-CoV-2. 3 Biotech 2021, 11, https://doi.org/10.1007/s13205-020-02578-7.

25. Moussa, N.; Hassan, A.; Singab, A. Quality control of herbal medicines used for arthritis: Identification and Quantification of COX Inhibitors by HPLC, GC-MS, LC-MS-MS, GC-FID. Acta Poloniae Pharmaceutica Drug Research 2021, 78, 157-167, https://doi.org/10.32383/appdr/134001.

26. Gong, G.; Guan, Y.-Y.; Zhang, Z.-L.; Rahman, K.; Wang, S.-J.; Zhou, S.; Luan, X.; Zhang, H. Isorhamnetin: A review of pharmacological effects. Biomedicine \& Pharmacotherapy 2020, 128, https://doi.org/10.1016/j.biopha.2020.110301. 
27. Jayadeepa, R.M.; Sharma, S. Computational Models for $5 \alpha$ R Inhibitors for Treatment of Prostate Cancer: Review of Previous Works and Screening of Natural Inhibitors of $5 \alpha \mathrm{R} 2$. Current computer-aided drug design 2011, 7, 231-237, https://doi.org/10.2174/157340911798260368.

28. Xiao, Q.; Wang, L.; Supekar, S.; Shen, T.; Liu, H.; Ye, F.; Huang, J.; Fan, H.; Wei, Z.; Zhang, C. Structure of human steroid $5 \alpha$-reductase 2 with the anti-androgen drug finasteride. Nature Communications 2020, 11, https://doi.org/10.1038/s41467-020-19249-z.

29. Maestro 9.9. Schrödinger, LLC.; New York: 2019. https://www.schrodinger.com/maestro. (Accessed on 15 September 2021).

30. Syed Sauban Ghani, S.S. A comprehensive review of database resources in chemistry. Eclética Química Journal 2020, 45, 57-68, https://doi.org/10.26850/1678-4618eqj.v45.3.2020.p57-68.

31. O'Boyle, N.M.; Banck, M.; James, C.A.; et al. Open Babel: An open chemical toolbox. J Cheminform 2011, 3, 33. https://doi.org/10.1186/1758-2946-3-33.

32. Harder, E.; Damm, W.; Maple, J.; Wu, C.; Reboul, M.; Xiang, J.Y. OPLS3: a force field providing broad coverage of drug-like small molecules and proteins. J. Chem. Theor. Comput. 2016, 12, 281-296, https://doi.org/10.1021/acs.jctc.5b00864.

33. Storer, J.W.; Giesen, D.J.; Cramer, C.J.; Truhlar, D.G. Class IV charge models: a new semi empirical approach in quantum chemistry. J. Comput. Aided Mol. Des 1995, 9, 87-110, https://doi.org/10.1007/BF00117280.

34. Madhavi, S.G.; Adzhigirey, M.; Day, T.; Annabhimoju, R.; Sherman, W. Protein and ligand preparation: parameters, protocols, and influence on virtual screening enrichments, J. Comput. Aided Mol. Des. 2013, 27, 221-234, https://doi.org/10.1007/s10822-013-9644-8.

35. Xiao, Q.; Wang, L.; Supekar, S.; Shen, T.; Liu, H.; Ye, F.; Huang, J.; Fan, H.; Wei, Z.; Zhang, C. Structure of human steroid $5 \alpha$-reductase 2 with the anti-androgen drug finasteride. Nature Communications 2020, 11, https://doi.org/10.1038/s41467-020-19249-z.

36. Friesner, R.A.; Banks, J.L.; Murphy, R.B.; Halgren, T.A.; Klicic, J.J.; Mainz, D.T.; Repasky, M.P.; Knoll, E.H.; Shelley, M.; Perry, J.K.; Shaw, D.E.; Francis, P.; Shenkin, P.S. Glide: A New Approach for Rapid, Accurate Docking and Scoring. 1. Method and Assessment of Docking Accuracy. Journal of Medicinal Chemistry 2004, 47, 1739-1749, https://doi.org/10.1021/jm0306430.

37. Friesner, R.A.; Murphy, R.B.; Repasky, M.P.; Frye, L.L.; Greenwood, J.R.; Halgren, T.A.; Sanschagrin, P.C.; Mainz, D.T. Extra Precision Glide: Docking and Scoring Incorporating a Model of Hydrophobic Enclosure for Protein-Ligand Complexes. Journal of Medicinal Chemistry 2006, 49, 6177-6196, https://doi.org/10.1021/jm051256o.

38. Chen, G.; Li, X.; Saleri, F.; Guo, M. Analysis of Flavonoids in Rhamnus davurica and Its Anti-proliferative Activities. Molecules 2016, 21, https://doi.org/10.3390/molecules21101275.

39. Abdul Latiff, N.; Suan, C.L.; Sarmidi, M.R.; Ware, I.; Abdul Rashid, S.N.S.; Yahayu, M. Liquid chromatography tandem mass spectrometry for the detection and validation of quercetin-3-o-rutinoside and myricetin from fractionated Labisia pumilavar. Alata. Malaysian J. Anal. Sci 2018, 22, 817-827, https://doi.org/10.17576/mjas-2018-2205-09.

40. Yuan, L.; Ding, M.; Ma, J.; Xu, J.; Wu, X.; Feng, J.; Zhou, X. Determination of finasteride in human plasma by liquid chromatography-electrospray ionization tandem mass spectrometry with flow rate gradient. Eur $J$ Drug Metab Pharmacokinet 2010, 35, 137-146, https://doi.org/10.1007/s13318-010-0013-x.

41. Panlin, Li.; Weiwei, Su.; Chengshi, Xie.; Zeng, X.; Peng, W.; Liu, M. Rapid Identification and Simultaneous Quantification of Multiple Constituents in Nao-Shuan-Tong Capsule by Ultra-Fast Liquid Chromatography/Diode-Array Detector/Quadrupole Time-of-Flight Tandem Mass Spectrometry. $J$. Chromatogr. Sci. 2015, 53, 886-897, https://doi.org/10.1093/chromsci/bmu137.

42. Li, A.; Hou, X.; Wei, Y. Fast screening of flavonoids from switchgrass and Mikania micrantha by liquid chromatography hybrid-ion trap time-of-flight mass spectrometry. Anal. Methods 2018, 10, 109-122, https://doi.org/10.1039/C7AY02103H.

43. Chen, Y.; Yu, H.; Wu, H.; Pan, Y.; Wang, K.; Jin, Y.; Zhang, C. Characterization and Quantification by LCMS/MS of the Chemical Components of the Heating Products of the Flavonoids Extract in Pollen Typhae for Transformation Rule Exploration. Molecules 2015, 20, 18352-18366, https://doi.org/10.3390/molecules201018352.

44. Lin, Y.; Wu, B.; Li, Z.; Hong, T.; Chen, M.; Tan, Y.; Huang, C. Metabolite Identification of Myricetin in Rats Using HPLC Coupled with ESI-MS. Chromatographia 2012, 75, 655-660, https://doi.org/10.1007/s10337-012-2239-z.

45. Ben Said, R.; Hamed, A.I.; Mahalel, U.A.; Al-Ayed, A.S.; Kowalczyk, M.; Moldoch, J.; Oleszek, W.; Stochmal, A. Tentative Characterization of Polyphenolic Compounds in the Male Flowers of Phoenix dactylifera by Liquid Chromatography Coupled with Mass Spectrometry and DFT. International Journal of Molecular Sciences 2017, 18, https://doi.org/10.3390/ijms18030512.

46. Chen, Y. Characterization and Quantification by LC-MS/MS of the Chemical Components of the Heating Products of the Flavonoids Extract in Pollen Typhae for Transformation Rule Exploration. Molecules 2015, 20, 18352-18366, https://doi.org/10.3390/molecules201018352. 
47. Wang, X.; Qian, Y.; Li, X.; Jia, X.; Yan, Z.; Han, M.; Qiao, M.; Ma, X.; Chu, Y.; Zhou, S.; Yang, W. Rapid determination of rosmarinic acid and its two bioactive metabolites in the plasma of rats by LC-MS/MS and application to a pharmacokinetics study. Biomed. Chromatogr. 2021, 35, https://doi.org/10.1002/bmc.4984.

48. Simirgiotis, M.J.; Benites, J.; Areche, C.; Sepúlveda, B. Antioxidant Capacities and Analysis of Phenolic Compounds in Three Endemic Nolana Species by HPLC-PDA-ESI-MS. Molecules 2015, 20, 11490-507, https://doi.org/10.3390/molecules200611490.

49. Chen, G.; Li, X.; Saleri, F.; Guo, M. Analysis of Flavonoids in Rhamnus davurica and Its Anti-proliferative Activities. Molecules 2016, 21, https://doi.org/10.3390/molecules21101275.

50. Tatar, G.; Salmanli, M.; Dogru, Y.; Tuzuner, T. Evaluation of the effects of chlorhexidine and several flavonoids as antiviral purposes on SARS-CoV-2 main protease: molecular docking, molecular dynamics simulation studies. Journal of Biomolecular Structure and Dynamics 2021, 1-10, https://doi.org/10.1080/07391102.2021.1900919.

51. Foddai, M.; Maldini, M.; Addis, R.; Petretto, G.L.; Chessa, M.; Pintore, G. Profiling of the Bioactive Compounds in Flowers, Leaves and Roots of Vinca sardoa. Natural Product Communications 2017, 12, https://doi.org/10.1177/1934578X1701200625.

52. Reed, K.A. Identification of Phenolic Compounds from Peanut Skin using HPLC-MS. December 7, 2009 Blacksburg, Virginia.

53. Sun, J.; Liang, F.; Bin, Y.; Li, P.; Duan, C. Screening Non-colored Phenolics in Red Wines using Liquid Chromatography/Ultraviolet and Mass Spectrometry/Mass Spectrometry Libraries. Molecules 2007, 12, 679693, https://doi.org/10.3390/12030679.

54. Xu, F.; Liu, Y.; Zhang, Z.; Yang, C.; Tian, Y. Quasi-MSn identification of flavanone 7-glycoside isomers in Da Chengqi Tang by high performance liquid chromatography-tandem mass spectrometry. Chinese Medicine 2009, 4, https://doi.org/10.1186/1749-8546-4-15.

55. Jung, U.J.; Kim, H.J.; Lee, J.S.; Lee, M.K.; Kim, H.O.; Park, E.J.; Kim, H.K.; Jeong, T.S.; Choi, M.S. Naringin supplementation lowers plasma lipids and enhances erythrocyte antioxidant enzyme activities in hypercholesterolemic subjects. Clinical Nutrition 2003, 22, 561-568, https://doi.org/10.1016/s02615614(03)00059-1.

56. Renugadevi, J.; Prabu, S.M. Naringenin protects against cadmium-induced oxidative renal dysfunction in rats. Toxicology 2009, 256, 128-134, https://doi.org/10.1016/j.tox.2008.11.012.

57. Den Hartogh, D.J.; Tsiani, E. Antidiabetic Properties of Naringenin: A Citrus Fruit Polyphenol. Biomolecules 2019, 9, 1-21, https://doi.org/10.3390/biom9030099.

58. Esposito, E.X.; Baran, K.; Kelly, K.; Madura, J.D. Docking of sulfonamides to carbonic anhydrase II and IV11Color Plate 1, Color Plate 2, Color Plate 3, Color Plate 4 for this article are on pages 307-308. Journal of Molecular Graphics and Modelling 2000, 18, 283-289, https://doi.org/10.1016/s1093-3263(00)00040-1.

59. Lucas, X.; Bauzá, A.; Frontera, A.; Quiñonero, D. A thorough anion- $\pi$ interaction study in biomolecules: on the importance of cooperativity effects. Chemical Science 2016, 7, 1038-1050, https://doi.org/10.1039/C5SC01386K.

60. Ferrari, L.; Stucchi, R.; Konstantoulea, K.; van de Kamp, G.; Kos, R.; Geerts, W.J.C.; van Bezouwen, L.S.; Förster, F.G.; Altelaar, M.; Hoogenraad, C.C.; Rüdiger, S.G.D. Arginine $\pi$-stacking drives binding to fibrils of the Alzheimer protein Tau. Nature Communications 2020, 11, https://doi.org/10.1038/s41467-019-137457.

61. Bender, O.; Atalay, A. Polyphenol chlorogenic acid, antioxidant profile, and breast cancer. Cancer Oxidative Stress and Dietary Antioxidants 2nd ed.; Victor, R.; Patel, V.B. Academic Press Elsevier: 2021; pp. 311-321, https://doi.org/10.1016/B978-0-12-819547-5.00028-6.

62. Kurczab, R.; Śliwa, P.; Rataj, K.; Kafel, R.; Bojarski, A.J. Salt Bridge in Ligand-Protein ComplexesSystematic Theoretical and Statistical Investigations. J. Chem. Inf. Model. 2018, 58, 2224-2238, https://doi.org/10.1021/acs.jcim.8b00266. 